\title{
Fluxo de capitais, valorização cambial e a ineficácia recente dos impostos sobre capitais externos no Brasil ${ }^{\dagger}$
}

\author{
Lucas Machado Ferreira* \\ Guilherme Jonas Costa da Silva*
}

\begin{abstract}
RESUMO - A crise mundial do subprime, resultado da acelerada desregulamentação do setor imobiliário e do próprio setor bancário nas duas últimas décadas, fez com que os grandes fundos de investimento buscassem mercados alternativos, entre os quais, o brasileiro. A entrada de capitais no país teve grande importância na explicação dos impactos da crise, pois comprometeu o potencial de crescimento de alguns setores. Com efeito, medidas de controles de capitais no Brasil foram necessárias, pois acreditava-se que seriam a melhor solução no curto prazo para manter o crescimento sustentado da economia brasileira, bem como para reduzir a vulnerabilidade externa e prevenir crises futuras. Contudo, os resultados observados aparentemente não foram os esperados, haja vista que a taxa de câmbio continuou se valorizando, prejudicando o setor exportador e o produto interno bruto doméstico.
\end{abstract}

Palavras-chave: Crise do subprime. Taxa de câmbio. Taxa de juros. Controles de capitais.

\section{INTRODUÇÃO}

O presente artigo tem por objetivo fazer uma discussão sobre a crise do subprime, seus desdobramentos e a ineficácia recente dos controles de capitais no Brasil.

A crise do subprime, amplamente discutida pela literatura, teve sua origem no mercado imobiliário norte-americano em 2007, notadamente na parte de hipotecas de alto risco. Esta crise resultou da acelerada desregulamentação do setor imobiliário e do setor bancário durante as últimas décadas. Em função dos seus efeitos, principalmente no setor bancário, e do aumento da interdependência entre as nações, esta crise rapidamente se espalhou pelo mundo e comprometeu o potencial de crescimento de várias economias.

Com o enfraquecimento desta crise, algumas economias, como a brasileira, vêm recebendo grandes volumes de capitais externos, resultado do descolamento da política monetária e da ausência de um planejamento adequado da magnitude e abrangência dessas medidas restritivas sobre determinados fluxos de capitais. Com efeito, a taxa de câmbio continuou se valori-

\footnotetext{
${ }^{*}$ Graduando em Ciências Econômicas do Instituto de Economia da Universidade Federal de Uberlândia. Endereço eletrônico: lucas_machado99@hotmail.com.

** Doutor em Economia pela Universidade Federal de Minas Gerais. É professor adjunto do Instituto de Economia da Universidade Federal de Uberlândia. Endereço eletrônico: guilhermejonas@yahoo.com.br.

† Os autores gostariam de agradecer os professores Fábio Henrique Bittes Terra e Cleomar Gomes da Silva, que generosamente comentaram a primeira versão deste trabalho, isentando-os, como de praxe, por erros e omissões remanescentes.
} 
zando, comprometendo as exportações e o mercado local, podendo desestabilizar a economia brasileira no médio ou longo prazo.

Para atingir o objetivo, além desta introdução, o trabalho está estruturado em quatro seções. A Seção 2 discute as origens da crise do subprime. Na sequência, apresentam-se os efeitos da crise financeira internacional. $\mathrm{Na}$ Seção 4, o debate volta-se para a política de combate a valorização cambial. Por fim, as considerações finais.

\section{OS ANTECEDENTES DA CRISE DO SUBPRIME SEGUNDO KRUGMAN (2009)}

Durante praticamente toda a década de 2000, as economias mundiais observaram um momento de grande estabilidade econômica. Este ambiente favoreceu o fortalecimento econômico-político das potências emergentes, dentre as quais se destacam o Brasil, a Índia e a China. Em função dessa relativa estabilidade na conjuntura internacional e das taxas de crescimento elevadas, esses países emergentes tornaram-se um destino certo do capital estrangeiro.

Entretanto, no começo de 2007, surgiram rumores de que a crise financeira nos EUA era iminente, o que de fato se concretizou e reverteu o cenário econômico internacional. Essa crise teve sua origem no mercado imobiliário, notadamente na parte de hipotecas de alto risco (subprime). Com o aumento da inadimplência do pagamento destes empréstimos baseados em crédito hipotecário, ocorreu uma forte contração da oferta de crédito para o setor, provocando uma queda nas vendas e no preço dos imóveis.

Em agosto de 2007, a crise imobiliária do mercado subprime atingiu os mercados financeiros e de capitais dos EUA e dos países da zona do euro, que tinham bancos ligados a essas hipotecas de alto risco. Segundo alguns autores, como Krugman, isto é resultado da acelerada desregulamentação do setor imobiliário e do próprio setor bancário, durante as duas últimas décadas, que permitiu o rápido crescimento das instituições autônomas de empréstimos hipotecários. Estas empresas buscaram a securitização dos seus contratos e venderam essas promissórias hipotecárias subprime aos fundos hedge, que são filiais de grandes bancos comerciais e de investimento norte-americanos e estrangeiros.

Krugman (2009) afirma que essa crise mundial veio se formando gradualmente desde os anos 1980, em função da criatividade dos bancos privados em burlar as regras de regulação. De acordo com o autor, as autoridades da economia norte-americana fizeram vistas grossas e deixaram os sintomas da crise evoluírem. Em 2007, os fundos e ativos financeiros ligados ao subprime iniciaram um efeito dominó que atingiu todo o mercado financeiro dos Estados Unidos. Em 2008, o Banco Central norte-americano (Federal Reserve) decidiu não ajudar algumas instituições endividadas, como o Lehman Brothers, o que afetou significativamente a confiança 
do mercado. Em poucos dias, as autoridades perceberam que a decisão havia sido desastrosa, já que a medida provocou um aprofundamento da crise de confiança, que se propagou rapidamente para as outras economias do mundo, reduzindo a liquidez internacional.

\section{A CRISE DO SUBPRIME E SEUS DESDOBRAMENTOS}

Com a instalação da crise mundial, houve uma redução significativa da liquidez internacional à disposição das economias emergentes, em particular, da economia brasileira, já nos primeiros trimestres de 2008. As linhas de crédito à exportação foram reduzidas de forma bastante pronunciada; consequentemente, o ritmo de crescimento das exportações e a aversão global ao risco produziram uma saída líquida de capitais do Brasil da ordem de US\$ 11 bilhões no último trimestre de 2008.

GRÁFICO 1 - CONTA CAPITAL E FINANCEIRA - SALDO - US\$ (MILHÕES)

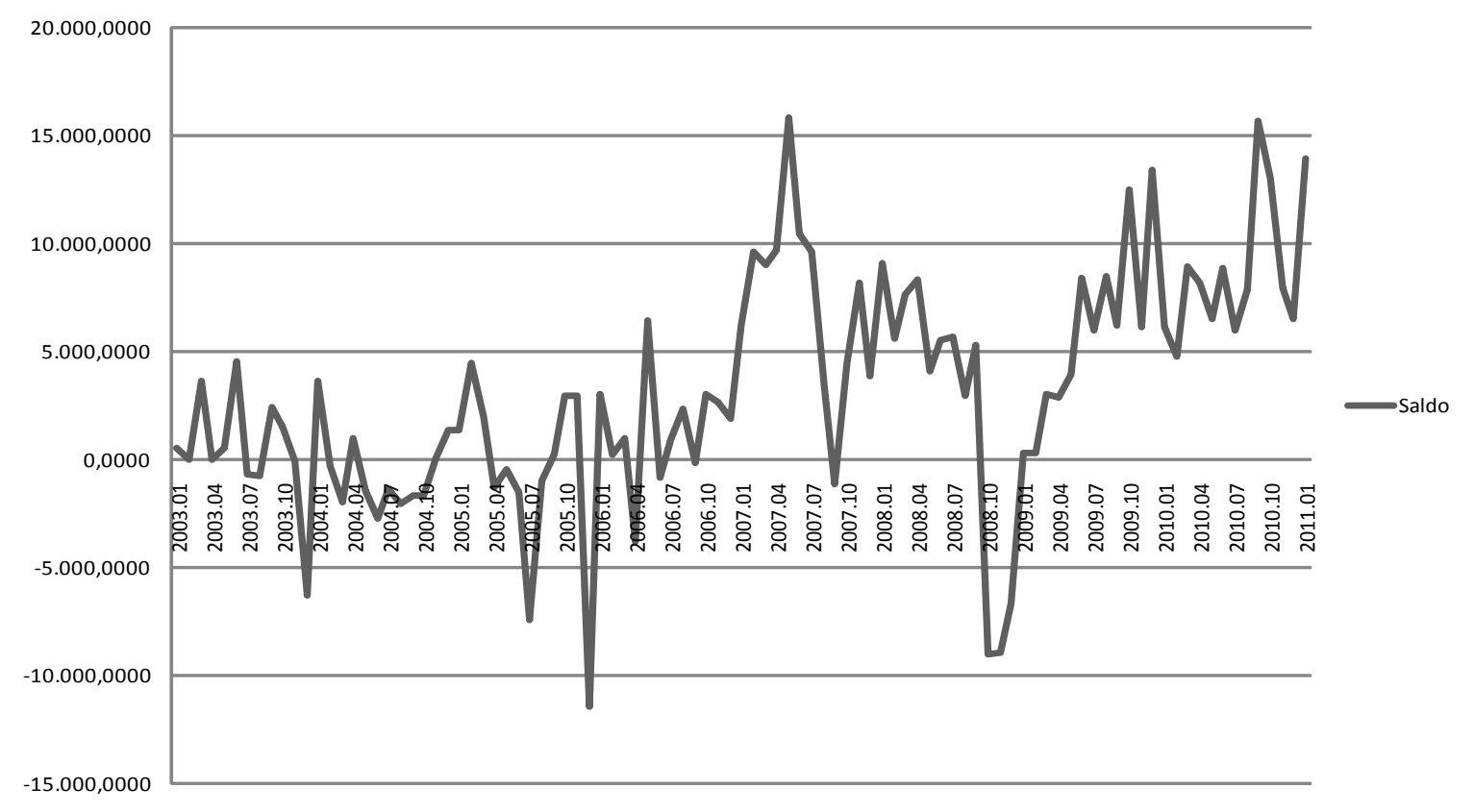

FONTE: Ipeadata.

Essa saída de capitais implicou em uma depreciação de 50\% do real frente ao dólar. A redução das linhas de crédito à exportação, a forte desvalorização da taxa nominal de câmbio e a saída de capitais do país produziram pânico entre os bancos brasileiros, levando-os a reduzir de forma significativa o crédito, tanto às pessoas físicas como jurídicas. A "evaporação do crédito" teve por consequência uma forte desaceleração do ritmo de crescimento dos gastos de consumo e o "engavetamento" de vários projetos de investimento no país (OREIRO; BASÍLIO; SOUZA, 2009, p. 3). 
O aumento na inadimplência no setor provocou uma crise de confiança sem precedentes, com isso as linhas de crédito voltadas para o subprime cessaram. Com todos os clientes de alto risco fora do mercado, o preço dos imóveis entrou em queda livre: do início da crise nos EUA em setembro de 2007 até março de 2009, houve um decréscimo de 25,86\% do preço agregado das casas, de acordo com o Índice Case Shiller.

\section{GRÁFICO 2 - ÍNDICE CASE SHILLER}

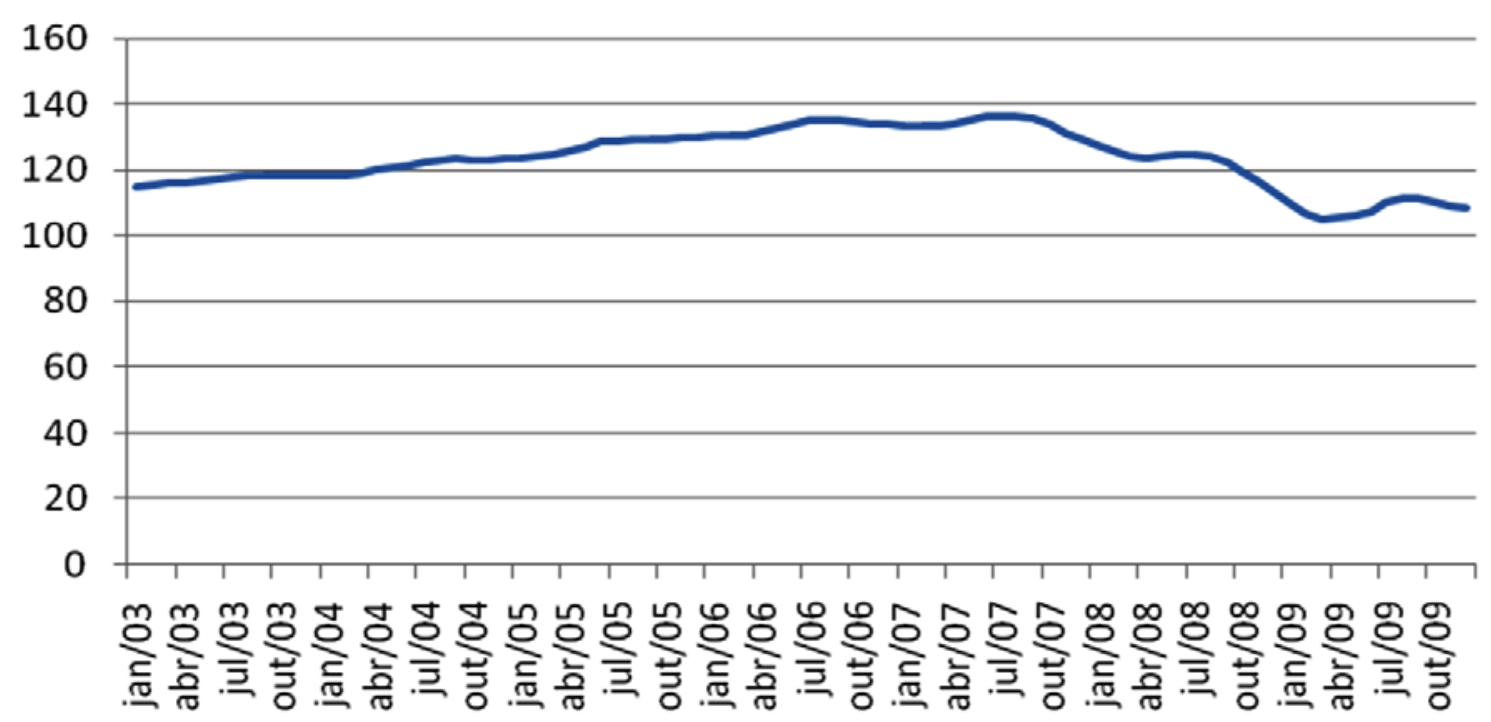

—Preço das Moradias - EUA

FONTE: Standard and Poors.

Os agentes financeiros ficaram sem os recursos necessários para saldar no tempo devido os seus passivos. Assim, verificou-se uma elevada descapitalização dos grandes bancos (deterioração de seus balanços) e uma forte diminuição da liquidez interbancária, que se propagou em razão da elevada incerteza.

Com efeito, a crise de liquidez estava posta e não tardou para que seus efeitos fossem sentidos em todos os setores da economia norte-americana. Em outubro de 2008, com a falência do Lehman Brothers, a crise de confiança se alastrou e causou estragos pelo mundo, fazendo com que os bancos comerciais aumentassem a sua preferência pela liquidez, reduzindo o volume de crédito e aumentando os spreads bancários.

No Brasil, essas medidas resultaram em quedas significativas no consumo de bens duráveis, mais especificamente, de automóveis e imóveis. Os setores automobilístico e imobiliário podem ser apontados como os mais prejudicados em função da maior dependência em relação ao setor bancário, por isso sofreram um grande choque, logo nos primeiros meses da crise mundial. 
As consequências dessa crise para as economias emergentes, apesar de alarmantes num primeiro momento, não comprometeram o potencial de crescimento de alguns destes países, fato que não se repetiu nos países ricos, que permanecem tecnicamente em recessão segundo o Relatório do Fundo Monetário Internacional sobre a Crise Mundial.

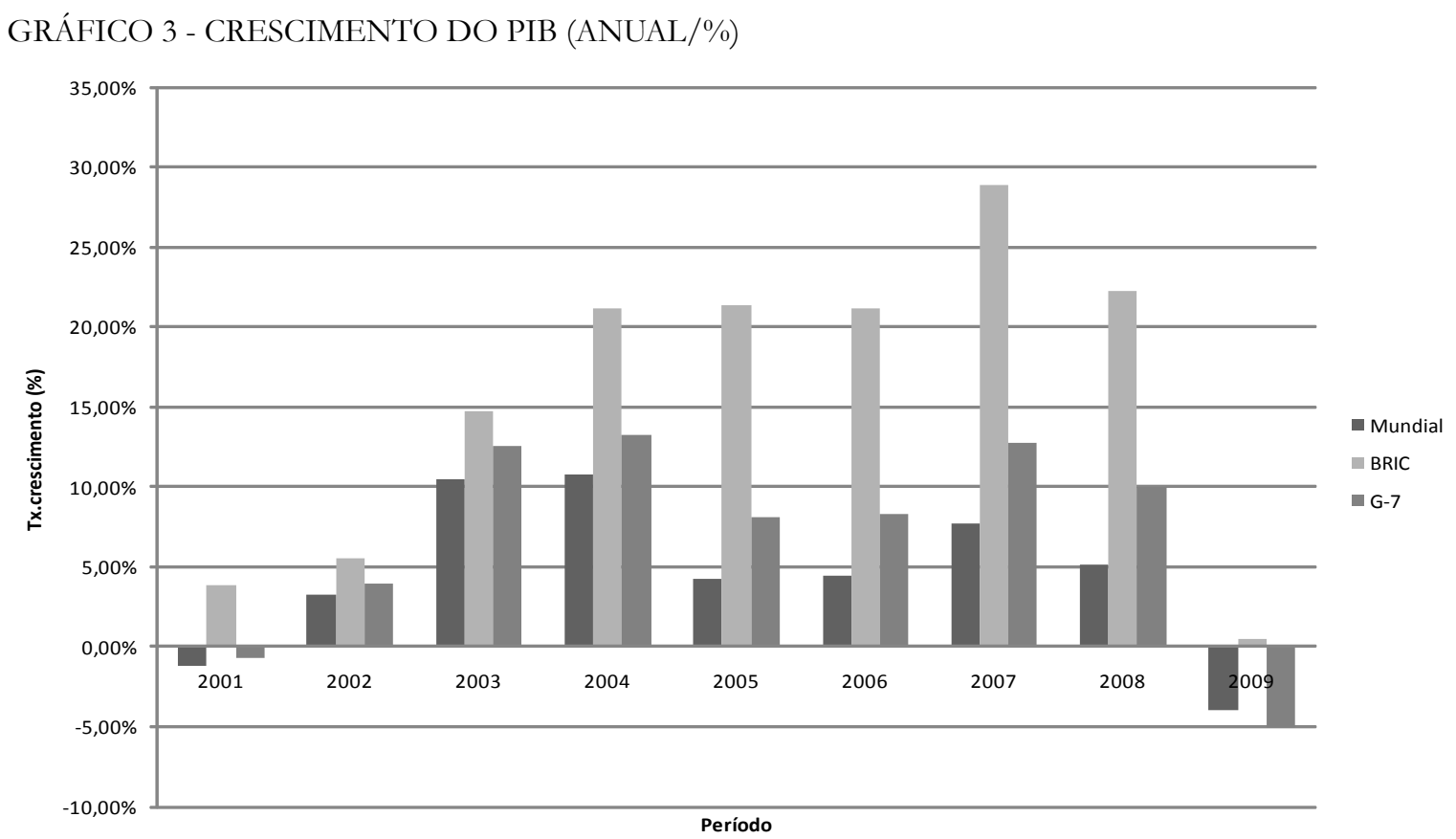

FONTE: World Bank Search.

Como se pode verificar no Gráfico 3, o PIB mundial se contraiu 1,91\% em 2009. Nos países do G-7 (EUA, Japão, Itália, Reino Unido, Canadá, Alemanha e França) a situação foi ainda pior, entrando com recessão de 3,95\% em 2009. Enquanto isso, os BRIC's obtiveram um desempenho macroeconômico positivo de $2,17 \%$.

\section{DA CRISE À RESSACA: UMA ANÁLISE DA POLÍTICA DE COMBATE À VALO- RIZAÇÃO CAMBIAL}

Contudo, no segundo semestre de 2009, quando a crise do subprime apresentava sinais de enfraquecimento e os fluxos de capitais voltaram aos países emergentes, o governo brasileiro decretou a imposição de uma alíquota do imposto sobre operações financeiras (Decreto 6.983/2009) nas aplicações em renda fixa e variável na ordem de $2 \%$, com o intuito de atenuar o ingresso de capitais e evitar uma valorização do câmbio. O resultado dessa política foi uma arrecadação acumulada no ano que já superava, em outubro de 2010, os R $\$ 5,574$ bilhões; portanto, um crescimento de 100\% em relação ao mesmo período do ano anterior. E mais, analisando o acumulado em 12 meses, tem-se o surpreendente valor de R 6,746 bilhões. Contudo, 
tais medidas não tiveram o efeito esperado, haja vista que o ingresso líquido de divisas no país ultrapassou os $\mathrm{R} \$ 50$ bilhões e a taxa de câmbio manteve sua trajetória, conforme demonstrado pelos Gráficos 4 e 5.

GRÁFICO 4 - EVOLUÇÃO DA TAXA DE CÂMBIO NO BRASIL: 2008 - 2010

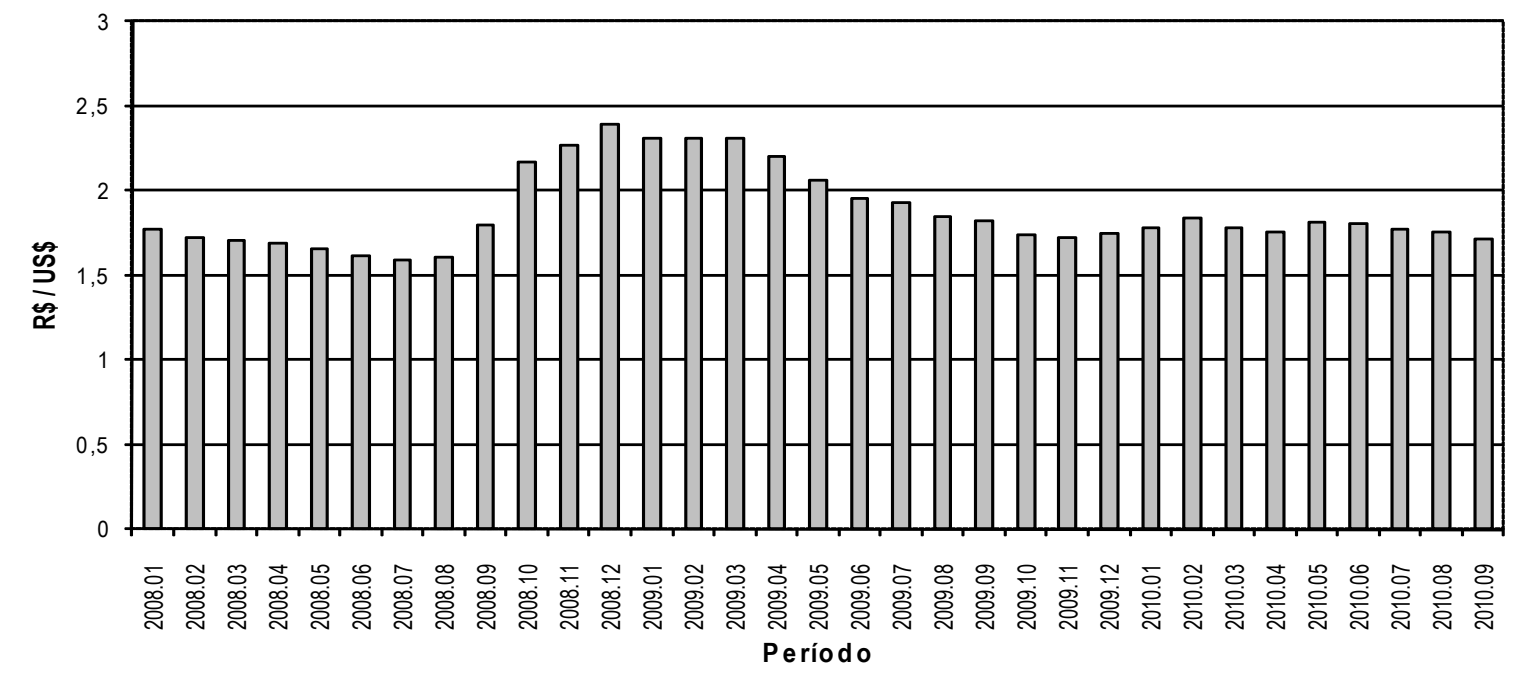

口Taxa de Câm bio - Comercial - Compra - Média

FONTE: Ipeadata.

GRÁFICO 5 - CONTROLES DE CAPITAIS NO BRASIL: 2008 - 2010

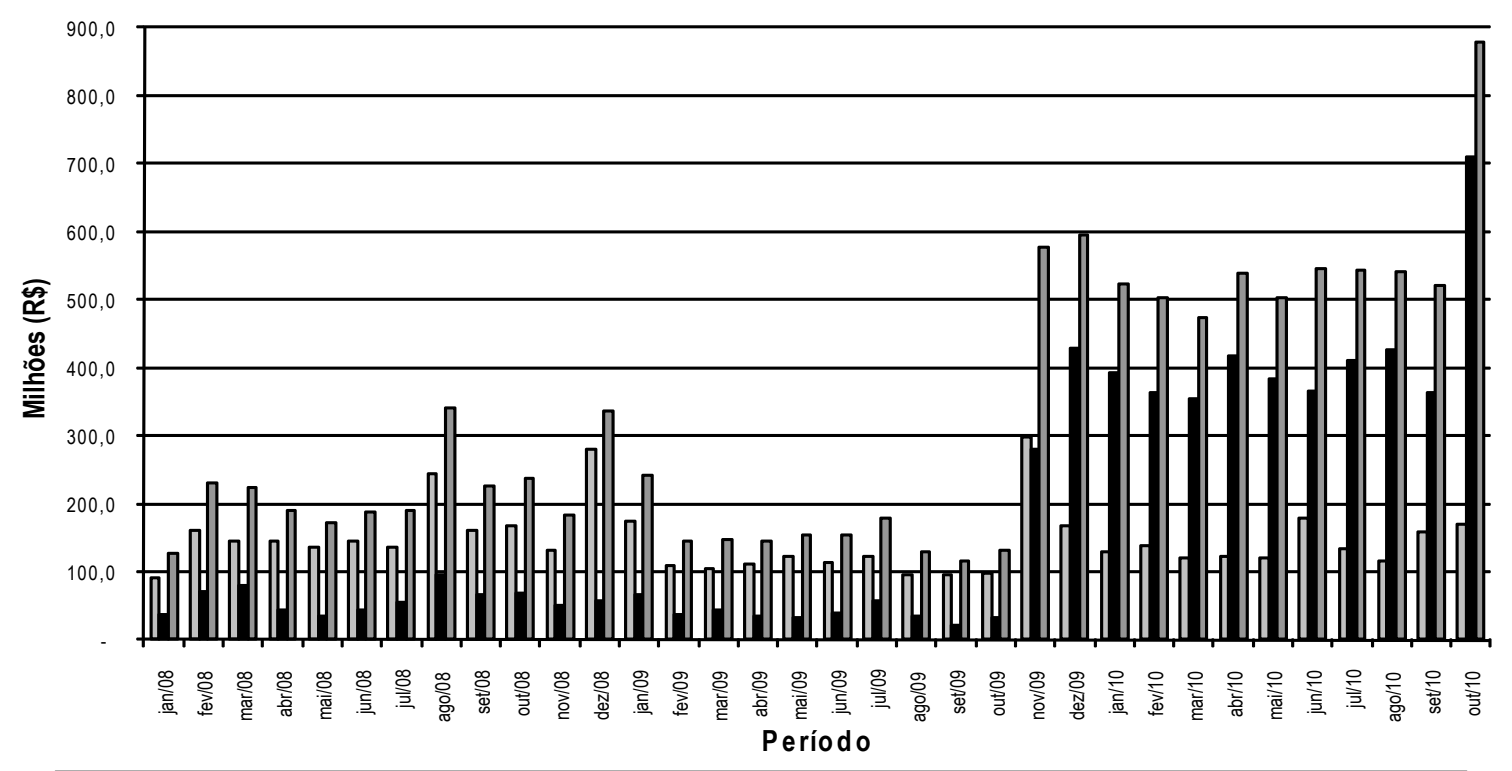

पIOF - Operações de Câmbio - Saida de Moeda GIOF - Operações de Câmbio - Entrada de Moeda $\quad$ alOF - Operações de Câmbio - Total

FONTE: Sistema Ângela (Receita Federal).

Esse elevado ingresso de capitais demonstra a grande atratividade que o país tem no mercado financeiro internacional, resultado dos bons fundamentos econômicos e do potencial de crescimento da economia brasileira, superior às expectativas de crescimento dos países do 
resto do mundo.

Se, por um lado, o ingresso excessivo continua preocupando o governo brasileiro, por outro o país tem uma das maiores taxa de juros do mundo, enquanto a taxa de câmbio segue uma persistente tendência de valorização, prejudicando as exportações e o mercado doméstico em função da concorrência dos produtos importados.

A fuga dos capitais da economia norte-americana e da recessão na Europa para as economias emergentes, em particular para a economia brasileira, aliada a uma elevada taxa de juros doméstica e uma taxa de câmbio valorizada, impôs ao governo duas opções: a necessidade de reduzir o patamar da taxa básica de juros ou adotar novas medidas de controles de capitais.

O governo aparentemente optou pela segunda alternativa, mas errou na dose. A operação de capitalização da Petrobras, a especulação em torno da descoberta do pré-sal, o ambiente econômico favorável e a guerra cambial exigiam medidas mais enérgicas sobre os capitais especulativos. No entanto, as autoridades apenas dobraram, no dia 06 de outubro de 2010 (Decreto 7.323/2010), a alíquota do IOF sobre os investimentos estrangeiros em renda fixa, de $2 \%$ para $4 \%$, ceteris paribus, na tentativa de reduzir o diferencial de juros e reverter a queda da taxa de câmbio. Evidentemente, os resultados não foram aqueles esperados pelas autoridades econômicas.

No primeiro momento, o governo brasileiro acreditava que a ineficácia dos controles de capitais era decorrente da capitalização da empresa estatal brasileira, entretanto, mesmo após essa operação de capitalização a taxa de câmbio continuou valorizando, forçando o governo a "reconhecer" que errou na magnitude e na abrangência dessas medidas, tanto que mais duas mudanças adicionais foram apresentadas no dia 18 de outubro (Decreto 7330/2010), quais sejam, um novo aumento do IOF, de $4 \%$ para $6 \%$, incidente sobre as operações de câmbio por investidores estrangeiros destinadas à aplicações de renda fixa, e um aumento de 0,38\% para 6\%, na alíquota do IOF nas operações de câmbio destinadas à constituição de margem de garantia exigidas por bolsas de valores, de mercadorias e futuros. A expectativa é que a arrecadação anual ultrapasse os 7 bilhões de reais e consiga definitivamente conter a tendência do dólar.

Ainda que a taxa de câmbio aumente ou mesmo se estabilize no curto prazo, acreditase que no médio ou longo prazo o dólar continuará a cair, já que é resultado da lenta recuperação dos Estados Unidos, que leva os grandes fundos de investimentos a buscar mercados mais rentáveis para suas aplicações, pressionando todas as moedas nacionais. Esse processo deve encerrar quando a economia norte-americana se recuperar e voltar aos patamares vigentes no pré-crise. Ademais, a pouca efetividade da política de controles de capitais no Brasil também é resultado do descolamento da política monetária e da ausência de um planejamento adequado 
da magnitude e abrangência dessas medidas restritivas sobre determinados fluxos de capitais, já que o volume de capitais externos entrando no país é muito grande. Enquanto não houver uma compreensão clara desse cenário internacional e uma mudança na estratégia do governo brasileiro, o setor exportador e o mercado nacional continuarão agonizando com a taxa de câmbio atual na declarada "guerra das moedas" para obter vantagens competitivas.

\section{CONSIDERAÇÕES FINAIS}

Após um período relativamente estável de crescimento, as economias mundiais enfrentaram uma grave crise financeira. No entanto, os resultados demonstram que algumas economias, inclusive a brasileira, superaram rapidamente esse momento de incerteza, retomando a trajetória de crescimento pré-crise.

As análises prévias demonstraram que as políticas de controle de capitais do país durante a recente crise mundial foram pouco eficazes, em função da baixa magnitude das alíquotas do imposto sobre operações financeiras e da ausência de um planejamento adequado dessas medidas restritivas sobre determinados fluxos de capitais. Com isso, o governo seria capaz de tornar os controles de capitais mais eficazes para manter a taxa de câmbio num patamar mais adequado, capaz de sustentar o saldo em transações correntes equilibrado, exigindo um superávit primário menor, e garantir uma margem de manobra para as autoridades monetárias utilizarem a taxa de juros para estimular o crescimento econômico sustentável.

\section{REFERÊNCIAS}

BRESSER-PEREIRA, L. C. Dominação financeira e sua crise no quadro do capitalismo do conhecimento e do Estado Democrático Social. Estudos Avançados, São Paulo, v. 22, n. 64, dez. 2008.

BRESSER-PEREIRA, L. C. Crise e recuperação da confiança. Revista de Economia Política, São Paulo, v. 29, n. 1, jan./mar. 2009.

CINTRA, M. A. M; FARHI, M. A crise financeira e o global shadow banking system. Novos Estudos, 2008.

INDICADORES macroeconômicos. Disponível em: < http://www.bcb.gov.br>.

INDICADORES macroeconômicos. Disponível em: <http:// www.ibge.gov.br $>$.

INSTITUTO de Pesquisa Econômica Aplicada. Disponível em: <http://www.ipeadata.gov. br/ipeaweb.dll/ipeadata?1423513625>. Acesso em: 10/2010.

KRUGMAN, P. R. A crise de 2008 e a economia da depressão. Rio de Janeiro: Elsevier, 2009.

NASCIMENTO, C.; SANTOS, J. P. C. A crise financeira internacional e os impactos nas economias brasileira e baiana. Conjuntura \& Planejamento, 2008. 
OCAMPO, J. A. O colapso do sistema financeiro mundial. Estudos Avançados, São Paulo, v. 22 , n. 64, dez. 2008.

OREIRO, J. L.; BASÍLIO, F. A. C.; SOUZA, G. A crise econômica mundial e a retomada do desenvolvimento no Brasil. 2009.

OREIRO, J. L. C.; PAULA, L. F. R.; SILVA, G. J. C. Fluxos e controle de capitais no Brasil: avaliação e proposição de política. In: PAULA, L. F.; OREIRO, J. L. C.; SICSÚ, J. (Org.). Agenda Brasil: políticas econômicas para o crescimento com estabilidade de preços. 1. ed. Rio de Janeiro: Manole, 2003. v. 1, p. 65-115.

RICUPERO, R. A crise financeira e a queda do muro de Berlim. Estudos Avançados, São Paulo, v. 22, n. 64, dez. 2008.

RECEITA Federal. Disponível em: <http://www.receita.fazenda.gov.br/Legislacao/Decretos $>$. Acesso em: 10/2010.

SILVA, G. J. C. Controle de capitais, dinâmica das exportações e performance macroeconômica das economias emergentes. Revista Economia e Desenvolvimento, Recife, v. 7, n. 1, p. 7-44, 2008.

SILVA, G. J. C.; RESENDE, M. F. C. Eficácia dos controles de capitais no Brasil: uma abordagem teórica e empírica alternativa. Estudos Econômicos, São Paulo, v. 40, p. 617-649, 2010.

STANDARD Poors. Disponível em: <http://www.standardandpoors.com>. Acesso em: $3 / 2011$.

WORLD Bank. Disponível em: < http://search.worldbank.org/data>. Acesso em: 10/2010. 
